ESTUDIOS

\title{
A mediação: A resolução 174 do Conselho Superior da Justiça do Trabalho e as disputas trabalhistas
}

\author{
Mediation: Resolution 174 of the Superior Council of Justice of Work and labor disputes
}

\author{
Fabiana Marion Spengler \\ Universidade de Santa Cruz do Sul, Brasil
}

\begin{abstract}
RESUMO O presente texto tem as práticas mediativas nas disputas trabalhistas como tema central, questionando: a mediação prevista na Resolução 174 do Conselho Superior da Justiça do Trabalho (CSJT) é meio viável e adequado para resolver disputas trabalhistas? A hipótese positiva que se propõe confirma a importância e a aplicabilidade da mediação no tratamento de disputas trabalhistas, mas discorda da abordagem e previsão de utilização conforme Resolução 174 haja vista que é procedimento realizado/supervisionado por um magistrado ou outro serventuário, equiparado e com pouca diferenciação da conciliação. Ao final as conclusões do texto confirmam a hipótese. Assim, os objetivos da pesquisa são: a) analisar a mediação a partir da Resolução 174 do CSJT, como meio hábil de resolver disputas trabalhistas; b) investigar se a proposta de mediação feita por um magistrado atende a base principiológica da mediação. Para fins de cumprir tais objetivos o método de abordagem utilizado foi o dedutivo. Como método de procedimento foi utilizado o método monográfico.
\end{abstract}

PALAVRAS-CHAVE Disputa trabalhista, processo, mediação, conciliação.

ABSTRACT The present text has the mediative practices in the labor disputes as the central theme, questioning: the mediation provided in Resolution 174 of the Superior Council of Labor Justice (CSJT) is a viable and adequate way to resolve labor disputes? The positive hypothesis proposed confirms the importance and applicability of mediation in the treatment of labor disputes but disagrees with the approach and prediction of use under the Resolution 174, since it is a procedure performed / supervised by a magistrate or other servant of the Justice System, similar and without differentiation of conciliation procedure. At the end, the conclusions of the text confirm the hypothesis. Thus, the objectives of the research are: a) to analyze mediation based on Resolution 174 of the CSJT, as a way to resolve labor disputes; B) investigate whether the proposal of mediation by a magistrate serves the basics of mediation. In order to fulfill the objec- 
tives the method of approach used was the deductive and, as method of procedure, the monographic one.

KEYWORDS Labor dispute, process, mediation, conciliation.

\section{Introdução}

É possível afirmar que as últimas décadas foram as «décadas da mediação» no Brasil. Especialmente a partir do início do século (anos 2000) foi possível observar a sua explosão: em terras brasileiras torna-se acalorado o debate a respeito da prática do procedimento mediativo. Importa referir que a mediação não se exprime somente nas relações interpessoais, mas naquelas que cada um pode ter com as instituições e, entre outras, com as administrações destas última (Chase, 2014: 69).

Assim, verifica-se o emprego - bastante equivocado em alguns momentos - do termo «mediação»; atualmente e especificamente a partir da Resolução 174 do Conselho Superior da Justiça do Trabalho (CSJT), existe uma preocupação cada vez mais expressa de achar meios para responder a um problema real: a mediação lá prevista (na Resolução do CSJT) é meio viável e adequado para resolver as disputas ${ }^{1}$ trabalhistas?

A hipótese positiva que se propõe confirma a importância e a aplicabilidade da mediação no tratamento de disputas trabalhistas mas discorda da abordagem e previsão de utilização conforme a Resolução 174 haja vista que é procedimento realizado/ supervisionado por um magistrado ou outro serventuário. Ao final as conclusões do texto confirmam a hipótese. Assim, a presente pesquisa tem as práticas mediativas nas disputas trabalhistas como tema central e objetiva: a) analisar a mediação a partir da Resolução 174 do CSJT, como meio hábil de resolver disputas trabalhistas; b) investigar se a proposta de mediação feita por um magistrado atende a base principiológica da mediação.

Para fins de cumprir tais objetivos o método de abordagem utilizado foi o dedutivo (Ventura, 2000), partindo da relação entre argumentos gerais, denominados premissas, para argumentos particulares, até se chegar a uma conclusão. Como método de procedimento foi utilizado o método monográfico, a partir da leitura e fichamentos de fontes bibliográficas diretas ligadas a pesquisa.

Justifica-se o debate do tema em questão por ser inovador ${ }^{2}$ e polêmico. Trata-se de proposta de tratamento de disputas trabalhistas que, na mesma esteira da Resolução

1. O termo «disputa» trabalhista será empregado seguindo a proposta da própria Resolução174 do CSJT que em seu art. $2^{\circ}$, inciso V, dispõe: V. Disputa» é a soma da questão jurídica e do conflito, assim considerada a partir da judicialização da lide.

2. A Resolução 174 do CSJT é data do dia 30 do mês de setembro de 2016. 
125 do CNJ, propõe outro caminho, anterior ou posterior a sentença judicial, porém atrelado ao Poder Judiciário, para lidar com conflitos processualizados. Por ser recente, o tema possui pouca produção bibliográfica e vem para arrefecer a discussão acerca do uso dos meios autocompositivos nas disputas trabalhistas. Porém, faz-se necessário salientar que nem todos os aspectos da Resolução 174 serão abordados, permanecendo a pesquisa centrada nos objetivos anteriormente definidos, ciente que de que a abordagem profunda da totalidade do texto demandaria limites espaço/temporais que ficam aquém de um artigo científico.

Nesse sentido e também a partir da Resolução 174 do CSJT3 ${ }^{3}$ observa-se que ocorreu, em muitos contextos, a banalização do termo mediação, utilizando-o para todo propósito. Mais do que banalizar o termo no sentido de utilizá-lo e propô-lo em todos os contextos, o que se observa é uma verdadeira «explosão» na sua utilização. Todos falam de mediação e muitos, subitamente, fazem mediação. Surgem em todos os Estados brasileiros cursos que pretendem, em poucas lições, «ensinar» um ofício tão importante e que depende também de habilidades natas do futuro mediador, que nem sempre podem ser desenvolvidas pelo supervisor ou professor de mediação.

No contexto jurídico e jurisdicional (e principalmente neles!) não foi diferente: a mediação começou a ser divulgada e implantada como meio miraculoso de tratar conflitos (todo e qualquer!), atribuindo ao mediador um poder quase sobrenatural de resolver as demandas. Ao mediador se atribui a possibilidade de encontrar consenso inclusive em disputas nascidas há décadas e transformadas em processo, cujas raízes e contornos encontram-se tão arraigados a ponto de se tornar quase impossível administrá-las sem o auxílio de uma equipe interdisciplinar e de anos de terapia, o que foge, em muito, ao modesto contexto mediativo atualmente vislumbrado.

Desconhecendo essas dificuldades, boa parte dos defensores e dos críticos da mediação seguem divulgando/criticando o procedimento, sem avaliar seus limites e suas possibilidades. Envolvida nessa aura miraculosa a mediação passa a ser vista como um «remédio para todos os males», meio absoluto de tratar e resolver conflitos, independentemente de sua origem e de seu contexto social. Se o processo não resolve, a mediação resolverá!

No primeiro item pretende-se trabalhar o conceito de mediação de modo geral e mais especificamente aquele direcionado ao contexto trabalhista. Aborda-se as diferenças entre mediação e conciliação ressaltando que dentro do procedimento Judiciário, ou fora dele, a conciliação é também uma forma de tratamento de disputas.

3. Críticas já foram feitas à Resolução 125/2010 do CNJ e as suas Emendas que, em moldes muito parecidos com a Resolução 174, instituiu a mediação como política pública adequada ao tratamento dos conflitos no âmbito do Judiciário e que também cometeu equívocos, dentre outros e inclusive, ao deixar de diferenciar, por exemplo, mediação e conciliação. Sobre o assunto ver Spengler e Spengler Neto (2013, 2016), Spengler (2016a, 2016b). 
No Brasil, ela é exercida por força de lei, conforme os arts. 139, V4 e $359^{5}$ do CPC, que preveem sempre a necessidade de proposta de conciliação em todas as demandas judiciais. Por outro lado, o conciliador privado nasce com a lei 9.958/oo. ${ }^{6}$ Esse conciliador é eleito pelos trabalhadores das empresas para compor comissões intersindicais de conciliação; neste caso, escolhidos por sindicatos dos trabalhadores e patronais.

Por fim, o artigo trabalha a figura do mediador trabalhista debatendo se ele pode ser o próprio magistrado ou um serventuário a ele vinculado, conforme prevê a Resolução.

Ciente da novidade e por isso da dificuldade de enfrentar um debate assim tão recente esse é, pois, o texto que agora se apresenta.

\section{Mas afinal, o que é mediação?}

A mediação judicial difere das práticas tradicionais de jurisdição justamente porque o seu objeto de trabalho é a sociedade, sendo a sua base de operações o pluralismo de valores, a presença de sistemas de vida diversos e alternativos, sua finalidade consiste em reabrir os canais de comunicação interrompidos e reconstruir laços sociais destruídos. O seu desafio mais importante é aceitar a diferença e a diversidade, o dissenso e a desordem por eles gerados. Sua principal ambição não consiste em propor novos valores, mas em restabelecer a comunicação entre aqueles que cada um traz consigo.

Tratando-se de mediação para Resolução de disputas trabalhistas, ela vem observada como alternativa para a instituição de um «espaço judicial» que implica a imposição de uma fronteira entre os que estão preparados para entrar no jogo e os que, quando nele se acham lançados, permanecem de facto dele excluídos, por não poderem operar a conversão de todo o espaço mental - e, em particular, de todo a postura linguística - que supõe a entrada neste espaço social (Bourdieu, 2006). Nesse sentido, a mediação pretende incluir todos os partícipes das disputas.

Como regra geral a mediação propõe a análise dos fatos não pela visão científica de um especialista e sim por seu relato e pela sua reconstrução espontânea, abordan-

4. Art. 139. O juiz dirigirá o processo conforme as disposições deste Código, incumbindo-lhe: V promover, a qualquer tempo, a autocomposição, preferencialmente com auxílio de conciliadores e mediadores judiciais (Lei 13.105 de 16 de março de 2015, Código de Processo Civil).

5. Art. 359. Instalada a audiência, o juiz tentará conciliar as partes, independentemente do emprego anterior de outros métodos de solução consensual de conflitos, como a mediação e a arbitragem ((Lei 13.105 de 16 de março de 2015, Código de Processo Civil).

6. A instalação e ao funcionamento da Comissão de Conciliação Prévia não é matéria pacífica. Existem questionamentos a respeito da constitucionalidade da lei 9.958/200o nos dissídios individuais (Testai, 2016; Barros, 2016). Porém a presente pesquisa não abordará esse tema em função dos limites espaciais e textuais aos quais foi dimensionada. 
do a «visão do caso» (Bourdieu, 2006). Porém, o desvio entre a visão vulgar daquele que se vai tornar um «justiciável» quer dizer, um cliente, e a visão científica do perito, juiz, advogado, conselheiro jurídico, etc., nada tem de acidental; ele é constitutivo de uma relação de poder, que fundamenta dois sistemas diferentes de pressupostos, de intenções expressivas, numa palavra, duas visões do mundo (Bourdieu, 2006).

Justamente por não trabalhar com uma matriz cuja base principal seja a formalidade e a ordem (aqui considerada como regramento estatal imposto), a mediação é alvo de duras críticas, sendo apontada como meio de fomentar o desequilíbrio entre os conflitantes, abrindo as portas para a coerção e a manipulação por parte do mais forte. Nesse sentido, um dos pontos de debate na presente pesquisa são as críticas tecidas em torno da mediação (enquanto prática não ritualizada de tratamento de conflitos) e da figura do mediador (enquanto «meio» que auxilia as partes estando «entre» elas e não «supra»).

Além disso, a mediação observa e respeita as diferenças dentro da realidade jurídica, indicando eficientes canais de comunicação entre o Direito e a sociedade. Assim, libertando-se das tentações de estabelecer dogmaticamente os critérios de decisão que se deve seguir na prática jurídica a mediação oferece ao Direito um procedimento que consegue dar conta da complexidade social, criando outras possibilidades para o tratamento dos conflitos.

Nestes termos, a proposta de praticar a mediação deveria ir além do acesso à justiça, aproximando o cidadão comum e «desafogando» o Poder Judiciário. Fazer mediação deveria ser um modo de lidar com o conflito não só quantitativamente, mas qualitativamente mais eficaz, proporcionando às partes a reapropriação da disputa, organizando o «tempo» e as "práticas» do seu tratamento, responsabilizando-se por tais escolhas e jurisconstruindo ${ }^{7}$ os caminhos possíveis.

A mediação pode organizar as relações sociais, auxiliando os conflitantes a tratarem suas disputas com autonomia, reduzindo a dependência de um terceiro (juiz), possibilitando o entendimento mútuo e o consenso. $\mathrm{O}$ consenso ${ }^{8}$ tem por base o fato

7. O termo «jurisconstrução» é um neologismo jurídico criado por José Luis Bolzan de Morais e que será objeto de maiores aprofundamentos no final do presente capítulo (Morais e Spengler 2019).

8. Porém, para que se fale de consenso - obtido a partir das práticas comunicativas advindas da mediação -, é importante que ele seja diferenciado dos conceitos de obediência e de consentimento. Assim, a obediência consiste na aceitação ou reconhecimento de um mando, independentemente de seus motivos determinantes ou justificados. Para sua caracterização, se faz necessário dois critérios: a aceitação externa e formal do mando. Ela constitui um pressuposto do político. Para a essência do político, pouco interessa se essa obediência é consentida ou forçada, se é dirigida a um regime democrático ou obtida por um regime autocrático. Já o consentimento é um conceito mais complexo que se aplica aos planos distintos do fundamento do poder e do seu funcionamento. No plano do fundamento, o consentimento proporciona a justificação do mando ou da obrigação política; no plano do funcionamento, o consentimento opera como uma forma de participação ou de influência da comunidade no poder. No 
de que toda sociedade suscetível de consistência e de duração supõe, de maneira contínua, a influência preponderante de um sistema prévio de opiniões comuns, próprio para conter o impulso impetuoso das divergências individuais. Sem esse sistema de opiniões prévias comuns, a tendência social é cair na anarquia, pela multiplicidade e pelo desencontro de opiniões. Assim, não se pode perder de vista que a noção de consenso $^{9}$ não se limita à concordância sobre crenças, valores, normas e objetivos, devendo ser usada amplamente para representar interdependência ou interconexão das partes de um contexto social.

É por isso que existem dúvidas quanto a necessidade de legislar sobre mediação. Nem todos aqueles que se ocupam da mediação concordam com a tão aclamada necessidade de juridificação através da criação de legislação específica que a regulamente, determinando seus objetivos, formas e possibilidades. O temor nasce da possibilidade de perda de seu caráter não decisionista e não autoritário de tratamento de conflitos (Castelli, 1996). O que não se pretende é ver cristalizadas as suas principais características que lhe permitem conservar a fluidez possibilitadora de adequação a situações diversas.

O risco de introduzir a mediação no sistema jurisdicional é reduzi-la à condição de um mero instrumento a serviço de um Sistema Judiciário em crise, mais do que da pacificação social. A sua institucionalização pode resultar útil se observada conforme critérios econômicos, mas perigosa de acordo com critérios jurídico-políticos. A alteridade da mediação quanto ao Direito nasce dos fins e dos princípios que a inspiram, de uma modalidade diversa de entendimento das relações interpessoais. Nestes termos, mediação e Direito propõem dois modelos diversos na forma, na estrutura decisional e nos princípios inspiradores (Cosi e Foddai, 2003).

Recepcionada no cenário jurídico brasileiro a mediação vem sendo praticada nos mais variados contextos: familiar, comunitário, escolar, hospitalar, judicial, empresa-

primeiro plano, o consentimento é uma força de obediência. O consentimento-aceitação é um sinal de legitimidade do poder como autoridade. A comunidade aceita espontaneamente o poder-autoridade, visando determinados fins básicos, porque essa estruturação e esses fins traduzem os valores mínimos fundamentais nela dominantes. Por fim, a noção de consensus é a condição da legitimidade, portanto do consentimento, no que concerne tanto ao fundamento do Poder, quanto ao seu funcionamento. Consensus, já vimos, é o acordo entre os membros da Comunidade, sobre as bases da ordem desejável (Souza Júnior, 2002).

9. A imprecisão do termo consenso é apontada por Horowits, que demostrou seu uso pelos defensores da teoria sociológica em vários sentidos diferentes, entre os quais se pode citar: a) ajustamento da dissensão social; b) acordo entre o papel de um comportamento e o papel dele esperado; c) crenças comuns, que ultrapassam as fronteiras dos grupos; e d) uma visão comum concernente à identidade ou congruência de desinteresses (Horowitz, 1962). Para a construção do presente texto, interessa mais a concepção de consenso enquanto meio de ajustamento da dissensão social, não obstante os demais aspectos serem mencionados. 
rial, dentre outros. Para a maioria desses contextos anteriormente a prática da mediação foi regrada mediante Resolução e/ou legislação. Outros, como aquele que envolve a mediação comunitária, possuem sua prática sem regramento específico que o ritualize. A mediação trabalhista também é um exemplo de prática mediativa regrada pela Resolução 174 do CSJT.

\section{E a mediação trabalhista?}

A mediação trabalhista pouco possui, até o presente momento, em termos de legislação específica que a determine. Até o mês de setembro de 2016, sua prática e a produção científica a esse respeito eram tímidas em todo o território nacional. Exceto pelo Decreto 1.572/95, ${ }^{10}$ pela Lei 10.192, de 2011, ${ }^{11}$ pela Convenção 98, de 1949, ${ }^{12}$ pelos artigos $18-\mathrm{B}^{13}$ da Resolução 125 do Conselho Nacional de Justiça (CNJ) e art. 42, parágrafo único, ${ }^{14}$ da Lei 13.140/2015 nada se dispunha a respeito. Atualmente, a Resolução do Conselho Superior da Justiça do Trabalho 174, de 30 de setembro de 2016 veio para suprir essa lacuna dispondo «sobre a política judiciária nacional de tratamento adequado das disputas de interesses no âmbito do Poder Judiciário Trabalhista» e dando outras providências.

Considerando-se que talvez o caminho utilizado não seja exatamente mediação e sim conciliação ou composição de conflitos trabalhistas, pela natureza das demandas e pelas características dos próprios conflitantes, o fato é que nessa área atualmente também se busca e se propõe (basta ver a Resolução 174 do CSJT) caminhos para respostas mais céleres e mais adequadas.

A Resolução em comento passa a fazer parte do cenário jurídico brasileiro no

10. Regulamenta a mediação realizada pelo Ministério do Trabalho e Emprego, na negociação coletiva trabalhista.

11. Art. 11. Frustrada a negociação entre as partes, promovida diretamente ou através de mediador, poderá ser ajuizada a ação de dissídio coletivo. $\$ 1^{\circ} \mathrm{O}$ mediador será designado de comum acordo pelas parte ou, a pedido destas, pelo Ministério do Trabalho e Emprego, na forma da regulamentação de que trata $\mathrm{o} \$ 5^{\circ}$ deste artigo. [...] $\$ 3^{\circ} \mathrm{O}$ mediador designado terá prazo de até 30 dias para a conclusão do processo de negociação, salvo acordo expresso com as partes interessadas. $\$ 4^{\circ}$ Não alcançado o entendimento entre as partes, ou recusando-se qualquer delas à mediação, lavrar-se á ata contendo as causas motivadoras do conflito e as reivindicações de natureza econômica, documento que instruirá a representação para o ajuizamento do dissídio coletivo. [...]

12. Art. $4^{\circ}$. Medidas apropriadas às condições nacionais serão tomadas, se necessário, para estimular e promover o pleno desenvolvimento e utilização de mecanismos de negociação voluntária entre empregadores ou organizações de empregadores e organizações de trabalhadores, com o objetivo de regular, mediante acordos coletivos, termos e condições de emprego.

13. Art. 18-B. O CNJ editará Resolução específica dispondo sobre a Política Judiciária de tratamento adequado dos conflitos de interesse da Justiça do Trabalho.

14. Art. 42. [...] Parágrafo único. A mediação nas relações de trabalho será regulada por lei própria. 
concernente aos conflitos trabalhistas tardiamente devido a polêmica que a proposta de autocomposição na justiça do Trabalho sempre gerou. A maior dificuldade na aplicação de meios compositivos na solução de conflitos trabalhistas se encontrava na divergência existente na doutrina. Existem posicionamentos de que as normas trabalhistas trazem direitos indisponíveis para o seu titular, por possuírem condão alimentar. Além disso, são direitos sociais que se apresentam como direitos humanos dos trabalhadores, possuindo, reconhecidamente, uma necessidade de cuidado e atenção especiais.

De acordo com Maurício Godinho Delgado (2019) a indisponibilidade dos direitos trabalhistas está vinculada ao direito individual de trabalho, realizando, a um só tempo, o princípio da imperatividade da legislação trabalhista. Essa indisponibilidade pode ser verificada em diferentes extensões: pode ser absoluta e relativa. A primeira acontece quando o direito discutido merecer uma tutela de interesse público porque traduz um patamar civilizatório mínimo formado pela sociedade em determinado momento histórico, como ocorre com o registro da relação de emprego na Carteira de Trabalho, o salário mínimo, as normas de proteção à segurança e à saúde do trabalhador, etc. No entanto, a indisponibilidade relativa versa sobre direitos que não correspondem ao referido patamar, como, por exemplo, a modalidade de salário (fixo ou variável), etc.

Merece destaque, ainda, o fato de que, independentemente da técnica empregada na solução dos conflitos trabalhistas, seja autocomposição ou heterocomposição, é preciso dar especial atenção para todos os requisitos e a validade da renúncia e da transação de direitos trabalhistas. Os requisitos são os clássicos colacionados no direito civil: capacidade do agente, higidez da manifestação da vontade, objeto válido e forma prescrita ou não proibida por lei (Delgado, 2019).

Mas, a renúncia, é, em regra, rechaçada pelo Direito do Trabalho, independentemente da existência ou não dos requisitos jurídico-formais, em decorrência do princípio da indisponibilidade e a aplicação do art. $9^{15}$ e $444,{ }^{16}$ da norma Consolidada. Raramente se admite transação, ocorrendo hipóteses taxativas previstas na ordem jurídica heterônoma estatal. Além dos limites dessas hipóteses, qualquer ato de renúncia do empregado, no direito do trabalhista, configura presunção de que foi coagido a praticá-lo.

Nesse sentido, a ponderação era de que, se o conflito não estivesse atrelado a norma de indisponibilidade absoluta a transação é possível. Vencido esse pressuposto, passa-se a verificação dos requisitos clássicos, supra mencionados (Delgado, 2019).

15. Art. $9^{\circ}$. Serão nulos de pleno direito os atos praticados com o objetivo de desvirtuar, impedir ou fraudar a aplicação dos preceitos contidos na presente Consolidação.

16. Art. 444. As relações contratuais de trabalho podem ser objeto de livre estipulação das partes interessadas em tudo quanto não contravenha às disposições de proteção ao trabalho, aos contratos coletivos que lhes sejam aplicáveis e às decisões das autoridades competentes. 
O fato é que, observados os comentários anteriores, e baseados na Lei 9.958, de 12/1/200o, que inseriu na Consolidação das Leis do Trabalho o Título VI-A, contendo os artigos 625-A a 625-H, foi autorizada a instituição das «Comissões de Conciliação Prévia», reconhecendo a existência dos Núcleos Intersindicais de Conciliação. Até a entrada em vigor da Resolução 174 a mediação (ainda que se insista: conciliação talvez seja o melhor mecanismo) vinha sendo feita conforme pode ser avistado em práticas divulgadas na rede internacional de computadores (Secretaria de Relações do Trabalho, 2016). ${ }^{17}$

Além disso, a própria Lei 13.140/2015, chamada de marco legal da mediação inseriu no seu art. $3^{18}$ a hipótese de se realizar a mediação em conflito que verse sobre direitos disponíveis ou indisponíveis que admitam transação. ${ }^{19} \mathrm{O}$ mesmo artigo no seu parágrafo $1^{\circ}$ dispõe que a mediação pode versar sobre todo o conflito ou sobre parte dele. Essa medida é salutar, pois dá a mediação uma flexibilidade de procedimento permitindo que todo o conflito ou somente parte dele seja objeto de diálogo e que, todo o conflito ou somente parte dele possa ser alvo de acordo. Assim os conflitantes podem mediar aquilo que pode ser mediado e o que não for possível é direcionado ao Judiciário. O dispositivo faz com que a voluntariedade em se manter no procedimento de mediação ou não impere também de modo parcial nesse caso. Conforme o parágrafo $2^{\circ}$, o consenso envolvendo direitos indisponíveis, porém transigíveis devem ser homologados em juízo, exigida a oitiva do Ministério Público quando houver interesse de incapazes. ${ }^{20}$

Desse modo, a hipótese de aplicar a autocomposição em direitos indisponíveis, mas transacionáveis está prevista na Lei 13.140/2015, autorizando e prevendo, nos artigos anteriormente mencionados, a possibilidade de acordo nas ações que envolvam direitos trabalhistas. A Resolução 174 do CSJT, por sua vez, não faz menção ao tipo de conflito a ser submetido a autocomposição, partindo-se do pressuposto que o envio

17. Secretaria de Relações do Trabalho, «Sistema de Negociações Coletivas de Trabalho - MEDIADOR», 2016, disponível em https://bit.ly/3fQJ9Mk.

18. Art. $3^{\circ}$. Pode ser objeto de mediação o conflito que verse sobre direitos disponíveis ou sobre direitos indisponíveis que admitam transação. $\$ 1^{\circ}$ A mediação pode versar sobre todo o conflito ou parte dele. $\$ 2^{\circ} \mathrm{O}$ consenso das partes envolvendo direitos indisponíveis, mas transigíveis, deve ser homologado em juízo, exigida a oitiva do Ministério Público (Lei 13.140, de 26 de junho de 2015. Dispõe sobre a mediação. Diário Oficial da União, Brasília, DF, 29 jun).

19. Sobre o assunto sugere-se a leitura de Spengler e Spengler Neto (2016).

20. "A incapacidade é a restrição legal ao exercício dos atos da vida civil, devendo ser sempre encarada estritamente, considerando-se o princípio de que "a capacidade é a regra e a incapacidade a exceção". [...] O instituo da incapacidade visa proteger os que são portadores de uma deficiência jurídica apreciável, graduando a forma de proteção que para os absolutamente incapazes (CC, art. $3^{\circ}$ ) assume a feição de representação, e para os relativamente incapazes (CC, art. $4^{\circ}$ ) o aspecto de assistência, já que têm o poder de atuar na vida civil, desde que autorizados» (Diniz, 2014: 170-171). 
dos processos para as centrais será feito conforme a pauta e a organização de cada magistrado.

$\mathrm{O}$ maior e mais intenso questionamento diz respeito a necessidade de que a mediação seja feita por mediador habilidoso e competente que consiga, usando de sua imparcialidade, equilibrar as partes gerando um relacionamento simétrico entre elas. Esse cuidado pode evitar: a) a assimetria do poder ${ }^{21}$ pois aquele que está em desvantagem sabe que, se a Resolução depende da autonomia, é possível que o acordo final requeira grandes concessões suas. Contudo, mediante a intervenção de uma autoridade que estabeleça a solução, a princípio, existe a confiança de não ocorrer pressões para que estas concessões aconteçam; e garantir a: b) a preservação das relações futuras, ${ }^{22}$ uma vez que se um dos conflitantes impõe sua posição ao outro, provavelmente prejudicará continuidade da relação futura (Soler, 2004).

Essa necessidade de simetria dentro da mediação encontra premência na justiça trabalhista devido o desequilíbrio financeiro, social e muitas vezes cultural existente entre empregado e empregador. Esse desequilíbrio pode acarretar na construção de um acordo desigual gerando prejuízos para a parte hipossuficiente. Nesse contexto, necessária e de grande importância também é a presença de um advogado que possa orientar a parte sobre a existência e os limites dos seus direitos.

\section{Mediação ou conciliação?}

A Resolução174 do CSJT ${ }^{23}$ institui a mediação e a conciliação como políticas públicas de tratamento adequado das disputas, diferenciando os dois institutos de maneira muito sutil.

21. Nesse sentido, o modo de assegurar uma adequada proteção à parte mais fraca dos conflitos é um problema ressaltado por Michele Taruffo, quando argumenta: «[...] nonché il problema di ammetere o di escludere la presenza dei diffensori, di una parte o di entrambi le parti. In ogni caso, sembra necessario che vi sia un procedimento 'visibile', guidato da regole predefinite, nel quale tutte le parti abbiano modo di far valere le loro pretese in modo adeguato. [...] informalità del procedimento non può significare disparità ed arbitrio» (Taruffo, 1999: 25).

22. Um tanto quanto paradoxal esta afirmação, uma vez que a mediação também pretende manter e proteger o relacionamento futuro entre os conflitantes, justamente por isso um dos seus objetivos é manter um canal aberto de comunicação entre eles.

23. Art. $1^{\circ}$. Para os fins desta Resolução, considera-se: I - «Conciliação» é o meio alternativo de Resolução de disputas em que as partes confiam a uma terceira pessoa - magistrado ou servidor público por este sempre supervisionado -, a função de aproximá-las, empoderá-las e orientá-las na construção de um acordo quando a lide já está instaurada, com a criação ou proposta de opções para composição do litígio; II - «Mediação» é o meio alternativo de Resolução de disputas em que as partes confiam a uma terceira pessoa - magistrado ou servidor público por este sempre supervisionado -, a função de aproximá-las, empoderá-las orientá-las na construção de um acordo quando a lide já está instaurada, sem a criação ou proposta de opções para composição do litígio. 
As diferenças entre mediação e conciliação são significativas e importantes. Elas se dão quanto à conceituação propriamente dita, mas também operam de modo expressivo no papel desempenhado pelos profissionais que administram as sessões, pelo tipo de conflito nelas tratados, pelos objetivos perseguidos e pelos resultados almejados.

Porém, antes de diferenciar mediação e conciliação faz-se necessário referir que ambas estão elencadas como métodos autocompositivos ${ }^{24}$ de tratamento dos conflitos, colocando-se em contraponto aos chamados heterocomposivos. ${ }^{25} \mathrm{~A}$ principal diferença entre autocomposição e heterocomposição diz respeito ao fato de que, enquanto nos processos heterocompositivos, cujos modelos são chamados adversariais (arbitragem e jurisdição) há sempre vencedores e vencidos (ganha/perde), nos processos autocompositivos de modelos consensuais (negociação, mediação e conciliação) buscam-se as soluções vencedoras (ganha/ganha), observando os interesses de todos (Bacellar, 2011). Tal se dá porque a mediação constitui um procedimento de transformação dos antagonismos em pontos de convergências, não necessariamente em pontos de concordância, mediante a intervenção de um terceiro escolhido pelos conflitantes. A mediação consiste em um «dos instrumentos de pacificação de natureza autocompositiva e voluntária, no qual um terceiro, imparcial, atua, de forma ativa ou passiva, como facilitador do processo de retomada do diálogo entre as partes, antes ou depois de instaurado o conflito». (Cahali, 2015: 85). O mediador tem, então, a tarefa de possibilitar que conflitantes expressem seus sentimentos e seus interesses dando a eles espaço para, de modo criativo, formular sugestões e propostas para a Resolução adequada de seu conflito. O mediador não tem papel ativo na proposição de acordos, nem na orientação das partes quanto ao conflito. Essa tarefa não é da sua alçada (Spengler, 2019b).

Já a conciliação é um instituto que tem por objetivo chegar voluntariamente a um acordo neutro e conta com a participação de um terceiro - conciliador - que intervém, podendo inclusive sugerir propostas para fins de dirigir a discussão. Na conciliação o objetivo é o acordo. Nela, as partes, mesmo adversárias, devem chegar a um acordo para evitar o processo judicial ou para nele pôr um ponto final, se por ventura ele já existe (Cahali, 2015). Justamente por isso, o conciliador sugere, orienta, interfere e aconselha as partes, sem analisar o conflito em profundidade (Spengler, 2019a).

24. «A autocomposição tem por princípios a indivisibilidade e a interpretação restritiva. Seu principal efeito é fazer desaparecer o litígio. Se judicial, dá causa ao fim do processo; se preventiva, evita-o. Os escopos da autocomposição são os mesmos do processo, de natureza jurídica, social e política, tanto em relação aos envolvidos quanto, indiretamente, à sociedade» (Cahali, 2015: 43).

25. «O processo heterocompositivo judicial abordava conflito como se fosse um fenômeno relacionado exclusivamente à estrutura normativa positivada e, ao tratar exclusivamente daqueles interesses juridicamente tutelados, excluía aspectos do conflito que são possivelmente tão importantes quanto ou até mais relevantes do que aqueles juridicamente tutelados. [...]» (Azevedo, 2011: 21). 
Ao delimitar conciliação e mediação, ${ }^{26}$ observa-se que a diferença básica entre ambas se encontra na origem do conflito (aqui analisado se ele diz respeito a uma relação continuada, com existência de relação anterior entre os conflitantes - cunho subjetivo-; ou se tratava de uma relação esporádica - de cunho objetivo), na postura do mediador/conciliador ou nas técnicas por ele empregadas (Cahali, 2015). Além disso, a conciliação tem por objetivo principal a pacificação do litígio processual mediante a elaboração de um acordo. Já a mediação pretende humanizar o conflito, restabelecendo a comunicação rompida entre os litigantes e tornando-a viável e, se possível, harmoniosa. O acordo é efeito secundário da mediação e não objetivo principal a ser perseguido como é o caso da conciliação (Spengler, 2019a).

Em síntese e de maneira bem objetiva, a mediação e a conciliação diferem:

a) quanto ao conflito: na conciliação existem conflitos esporádicos, sem relacionamento prévio ou posterior entre os conflitantes. Ex.: relações de consumo ou acidente de trânsito; já na mediação existem conflitos nos quais os envolvidos possuem relações próximas anteriores ao litígio e que permanecerão (pelo menos assim se espera), íntegros após a Resolução do mesmo. Exemplo típico são os conflitos do Direito de Família, Direito Sucessório ou aqueles pertencentes às relações de amizade e vizinhança; b) quanto ao papel do mediador/conciliador: na mediação há uma terceira pessoa que atua como mediador, ajudando os conflitantes a restabelecer a comunicação. O mediador não sugere, não propõe, não orienta. O conciliador, ao contrário, é o terceiro que pode sugerir, propor, orientar e direcionar o debate e seus resultados; c) quanto aos objetivos perseguidos: a mediação busca um tratamento adequado ao conflito que gere comunicação e satisfação dos envolvidos. $\mathrm{O}$ acordo pode ser uma consequência dessa dinâmica, mas um procedimento de mediação que não tenha se encerrado com um acordo não poderá ser chamado de inexitoso se possibilitou que os conflitantes voltassem a conversar. A mediação busca o consenso e a efetiva pacificação social. A conciliação tem por alvo principal alcançar o acordo, por isso é um procedimento focado na necessária composição entre as partes. O objetivo é solucionar o litígio mediante um acordo; d) quanto às técnicas empregadas e à dinâmica das

26. «Longe de pretender apresentar distinções definitivas entre formas autocompositivas de solução de conflitos, é importante trazer algumas reflexões distintivas entre conciliação e mediação a partir dos vínculos e relações entre as partes. A conciliação em um dos prismas do processo civil brasileiro é opção mais adequada para resolver situações circunstanciais, como uma indenização por acidente de veículo, em que as pessoas não se conhecem (o único vínculo é o objeto do incidente), e, solucionada a controvérsia, lavra-se o acordo entre as partes, que não mais vão manter qualquer outro relacionamento; já a mediação afigura-se recomendável para as situações de múltiplos vínculos, sejam eles familiares, de amizade, de vizinhança, decorrentes de relações comerciais, trabalhistas, entre outros. Como a mediação procura preservar as relações, o processo mediacional bem conduzido permite a manutenção dos demais vínculos, que continuam a se desenvolver com naturalidade durante e depois da discussão da causa» (Bacellar, 2011: 35-36). 
sessões: a mediação prevê o emprego de técnicas voltadas para a escuta e o desvelamento do real interesse envolvido no conflito. É um procedimento voltado aos conflitantes que se tornam protagonistas de suas histórias e da construção de respostas aos seus problemas. A mediação prevê sessões mais longas do que a conciliação, bem como a remarcação de tais sessões quando é necessário que o diálogo se mantenha e amadureça para que posteriormente sejam tomadas as decisões. Já a conciliação prevê o uso de técnicas de negociação mais voltadas para o acordo propriamente dito, ela estimula propostas e contrapropostas dos conflitantes e do conciliador. A conciliação acontece em sessões mais curtas e a hipótese de remarcação de novos encontros não é tão frequente (Spengler, 2019a; Spengler, 2019b).

Diante do exposto observa-se que mediação e conciliação são institutos afins, porém, diferentes. Cada um deles possui seus limites e possibilidades servindo a conflitos específicos, com características e formas de atuação também diferenciadas. Por isso distingui-los é importante. A Resolução 125 não soube fazer essa distinção, tratando-os da mesma maneira perpetuou a confusão já existente. Já a Resolução 174 diferencia conciliação e mediação utilizando na qual conciliação e mediação são descritas quase do mesmo modo, existindo apenas duas palavras que diferenciam os termos: «com»e «sem». ${ }^{27}$

Além disso, importa referir que a conciliação já vinha sendo posta em prática no país. Implantar a mediação foi tarefa postergada para depois do pleno funcionamento da conciliação. Os argumentos a esse respeito justificavam a decisão, afirmando que é mais fácil treinar conciliadore ${ }^{28}$, que a conciliação já é instrumento conhecido pelos operadores do direito ${ }^{29}$, que ela serve a uma esfera mais ampla de conflitos a serem tratados, dentre outros.

Assim, o que se verifica é a existência de uma grande confusão entre os institutos da mediação e da conciliação que na área trabalhista se mantém e que pode gerar a má utilização dessas práticas. Em boa parte das disputas trabalhistas a conciliação é mecanismo adequado em função principalmente do anteriormente elencado. Porém, a mediação pode ser interessante e bem-vinda nas disputas que envolvam relações trabalhista e ao mesmo tempo familiares ou de amizade.

27. Art. $1^{\circ}$ Resolução 174 CSJT: Para os fins desta resolução, considera-se: I. «Conciliação» é o meio alternativo de resolução de disputas em que as partes confiam a uma terceira pessoa - magistrado ou servidor público por este sempre supervisionado -, a função de aproximá-las, empoderá las e orientá-las na construção de um acordo quando a lide já está instaurada, com a criação ou proposta de opções para composição do litígio; II. «Mediação» é o meio alternativo de resolução de disputas em que as partes confiam a uma terceira pessoa - magistrado ou servidor público por este sempre supervisionado -, a função de aproximá-las, empoderá-las e orientá-las na construção de um acordo quando a lide já está instaurada, sem a criação ou proposta de opções para composição do litígio;

28. Realmente o número de horas-aula teóricas e práticas é menor.

29. Antes mesmo da Resolução 125 a «Semana da Conciliação» já ocorria em todo o país. 


\section{Juiz mediador?}

A Resolução 174 do CSJT traz, no seu artigo $1^{\circ}$, o conceito de mediação e de conciliação ressaltando que elas são feitas por uma terceira pessoa, na qual as partes confiam que pode ser um «magistrado ou servidor público por este sempre supervisionado».

$\mathrm{O}$ artigo em comento em seus dois primeiros incisos traz claramente uma proposta de mediação e de conciliação que foge aos padrões até então divulgados e utilizados em solo brasileiro. Os incisos I e II do artigo $1^{\circ}$ dispõe sobre o terceiro que poderá ser o juiz ou então um servidor público por ele supervisionado e que terá a incumbência de fazer mediação/conciliação.

Os dois incisos deixam claro a possibilidade do conciliador orientar as partes na construção de um acordo, coisa que só é cabível/possível na atuação do conciliador. Sabe-se que não cabe a esse terceiro imparcial decidir pelas partes ou obriga-las a firmar acordo. Tal se dá porque o mediador/conciliador é um terceiro que se coloca entre as partes, não acima delas e que não possui a prerrogativa de decidir conflitos. Essa prerrogativa é direcionada somente aos magistrados, recordando que mediador/ conciliador que sugere, orienta, decide e obriga a fazer acordo é aquele que não conhece sua missão e nem o seu Código de Ética.

Aqui reside a grande diferença entre o papel a ser desempenhado pelo juiz e aquele atribuído a mediadores e conciliadores dentro da disputa. Assim, para possibilitar que o juiz exerça sua função, «é imperativo abstrair-se da relação conflitual». Só um terceiro, isto é, uma personagem que não está totalmente submerso no conflito, pode tornar os parceiros iguais por estarem equidistantes entre si. Observa-se então que "para formar uma linha, são precioso dois pontos; a criação de um espaço necessita de um mínimo de três» (Garapon, 1997: 102). O juiz, para triangularizar as relações sociais «deve situar-se à margem do mundo. Ele só pode ordenar as relações desse mundo assinalando, simultaneamente, o seu distanciamento em relação ao mesmo». Esse «distanciamento» é conferido pelo ritual judiciário e caracterizado pela «ruptura do espaço judiciário com o espaço cotidiano, ruptura do tempo do processo com o tempo cotidiano, ruptura do sujeito judiciário que, ao vestir a toga, se torna uma pessoa alegórica» (Garapon, 1997: 102-103).

Nestes termos quando se litiga judicialmente, ao juiz pede-se que cumpra seu papel de terceiro no conflito e «decida», que diga a última palavra com base na lei, e não que desenvolva a tarefa de cimento social que compete a outros mais preparados (mediador/conciliador). Quando o juiz assume outro papel (Spengler, 2019b), dividindo-se na função de decidir ou de mediar/supervisionar uma mediação o resultado, sabe-se, é paradoxal: incorpora-se no interior das competências judiciárias um gênero de procedimento e de linguagem que foge a competência e a legitimidade estatal, embocando, obviamente, em uma estrada errada. Os sintomas da inadequação na duplicidade de funções (mediar e decidir) são percebidos de modo incisivo e 
questionados, especialmente, quanto a neutralidade e a imparcialidade exigida de um juiz que, em não ocorrendo acordo na mediação ou na conciliação, deverá decidir o conflito. Essas constatações podem macular a validade da mediação/conciliação feitas por inobservância de seus princípios mais singelos.

A lei substitui a violência privada ou sacrifical, determinando posições e tornando-se exigível e coercível. A ordem e a segurança dependem, assim, não só da validade da solução adotada como do consenso entre as partes e, principalmente, da eficácia do seu aparato de coerção. Contudo, os contendentes podem não estar satisfeitos e as raízes do conflito não estarem extirpadas, mas a paz do Direito funcionará repousando sobre a sua capacidade impositiva. Como certos remédios, o Direito, pelo exercício da magistratura, parece capaz de tratar, sobretudo, os sintomas e não as causas do conflito (Cosi, 2004). A mediação atua de modo oposto, sem coerção ou imposição.

O papel desenvolvido pelo mediador é o de proximidade, de estar no «meio do conflito», nem acima e nem distante e sim no «meio». Cabe ao mediador restabelecer a comunicação interrompida entre os conflitantes, fomentar o diálogo, permitir a criação de opções geradoras de uma(s) resposta(s) adequada(s) para a disputa. É importante considerar que o mediador exerce papel «fundamental para o bom andamento do processo de mediação» (idem com relação ao conciliador e a conciliação). Tal se dá porque ele deve ser imparcial, isto é, aquele que, sem emitir juízo de valor, auxilia as partes a conversarem. O mediador «procura reestabelecer o relacionamento, atuando como um catalizador, procurando potencializar o positivo do conflito» (Maluf e Miranda, 2013: 22).

Observa-se também que o mediador é considerado o terceiro elemento que se encontra «entre» os conflitantes e que se dispõe a ajudá-los a buscar uma resposta consensuada e estruturada de maneira que permita ser possível a continuidade das relações entre as pessoas involucradas no conflito (Haynes, 1993). Trata-se de uma «gestão ativa de conflitos pela catálise de um terceiro» através de uma «técnica mediante a qual são as partes mesmas imersas no conflito quem tratam de chegar a um acordo com a ajuda do mediador, terceiro imparcial que não tem faculdades de decisão» (Six, 2001: 191).

Tal se dá porque o terceiro mediador se posiciona em meio as partes partilhando de um espaço comum e participativo, voltado para a construção do consenso num pertencer comum. A mediação é uma arte na qual o mediador não pode se preocupar em intervir na disputa, oferecendo às partes liberdade para tratá-lo. Ao contrário do juiz, a figura do mediador não possui papel central; via de regra, possui papel secundário, poder de decisão limitado; ele não pode unilateralmente obrigar as pessoas a resolverem a contenda ou impor decisão. Deve mediá-las, conciliar os interesses conflitivos, conduzindo para que elas concluam com o seu impulso qual é a melhor solução. 
O fim da mediação é exatamente responsabilizar os conflitantes pelo tratamento da disputa que os une a partir de uma ética da alteridade, encontrar, com o auxílio de um mediador, uma garantia de sucesso, aparando as arestas e divergências, compreendendo as emoções reprimidas e buscando um consenso que atenda aos interesses das partes e conduza à paz social (Torres, 2005).

Nesse sentido, a dúvida que se instala então é a respeito da habilidade de magistrados e serventuários (da ativa, ou aposentados) de fazer mediação/conciliação, cujo viés e o resultado esperado são tão diferenciados das suas atividades cotidianas ${ }^{30}$. Do magistrado se espera a decisão, a última palavra e não mediação ou conciliação. $\mathrm{Na}$ lógica do Judiciário trabalha-se com a ideia de transferência de responsabilidades quanto à gestão do conflito que vai direcionada ao juiz que o traduz na linguagem dele. ${ }^{31}$ Desse modo, partindo do processo de racionalização weberiana, o Estado, ao deter a forma de poder legal, detém, também, o monopólio legítimo da decisão vinculante (Weber, 1999). Assim, as atenções continuam centradas na figura do juiz, do qual se espera a última palavra, «não importa qual, mas a última». O lugar do juiz entre os conflitantes é uma questão complicada, uma vez que ele não se deixa encerrar na fácil fórmula da lei que assegura «distância de segurança» das razões de um e do outro. Ele vive no conflito e do conflito que ele decide, pronunciando a última palavra e não necessariamente promovendo o diálogo e o consenso.

\section{Conclusão}

A conciliação já era prática nas disputas trabalhistas e ganhou força, ao lado da mediação, a partir da Resolução 174 de setembro de 2016. Trabalhando sob esse tema como eixo central o presente texto desenvolveu os objetivos propostos na sua introdução e confirmou a resposta lá também disposta.

Assim, respondendo objetivamente ao problema de pesquisa formulado é possí-

30. Importante salientar que não se põe em dúvidas, em nenhum momento, a capacidade cognitiva dos magistrados e serventuários, profissionais que adentram ao Judiciário depois de um árduo processo de seleção no qual seus conhecimentos são testados exaustivamente. Porém, eles são formados nas universidades na cultura do conflito que sempre direciona os litígios para o processo e, consequentemente, para a sentença. Posteriormente são concursados e treinados para processar e decidir. É isso que se espera, por exemplo, de um juiz. Por outro lado, sabe-se que existe uma sobrecarga de trabalho atribuída a eles: milhares de processos que aguardam seu impulso e sua decisão. Por que sobrecarregá-los mais ainda com outros afazeres? Por que não atribuir a eles o trabalho para o qual foram selecionados?

31. Isso se dá, segundo Maurice Blanchot, porque o juiz tem o direito de ser único maître du langage. A expressão maître du langage é decisiva e densa, como pode ser aquela de um pensador como Maurice Blanchot, que trabalhou de maneira muito convincente sobre o poder da escrita e sobre a ideia de comunidade. A conexão entre linguagem e comunidade não é, obviamente, imprevista, mas encontrar ligações e mediações através do juiz abre caminhos insuspeitos por meio dos quais se descobre que a linguagem da comunidade não corresponde nunca à comunidade de linguagem (Blanchot, 1996). 
vel afirmar que a mediação prevista na Resolução 174 do CSJT é sim um meio viável e adequado para resolver disputas trabalhistas. Porém, a partir da resposta afirmativa ao problema de pesquisa algumas premissas podem ser expostas:

a) é preciso racionalizar a mediação como mecanismo de administrar conflitos considerando que ela é adequada em termos qualitativos para lidar com as disputas trabalhistas; importante observar que, como qualquer outro meio, a mediação possui falhas, interpretações equivocadas, utilização errônea e necessidade de revisão, ajuste e amadurecimento para que atinja o seu auge (em termos de aplicação e produtividade qualitativa e não só quantitativa/numérica).

b) observar que existem diferenças importantes entre mediação e conciliação, que foram esquecidas pela Resolução 174 do CSJT, e que a principal reside no conteúdo de cada instituto. Na conciliação, o objetivo é o acordo, ou seja, as partes, mesmo adversárias, devem chegar a um acordo para evitar o processo judicial ou para nele pôr um ponto final, se por ventura já existe. Na conciliação, o conciliador sugere, interfere, aconselha, e na mediação, o mediador facilita a comunicação sem induzir as partes ao acordo. Na conciliação, se resolve o conflito exposto pelas partes sem analisá-lo com a mesma profundidade proposta pela mediação.

Levando em consideração tais argumentos, mais do que propor e fazer mediação, torna-se necessário fazer uma triagem adequada das disputas trabalhistas a ela submetidas para que se faça mediação onde e quando for cabível e conciliação em outros contextos;

c) é importante salientar que para que seja exitoso o procedimento de mediação, é necessário que exista equilíbrio das relações: não obterá êxito a mediação na qual as pessoas estiverem em desequilíbrio de atuação. É fundamental que a todos seja conferida a oportunidade de se manifestar e garantida a compreensão das ações que estão sendo desenvolvidas. A prioridade do processo de mediação é a restauração da harmonia. Buscar-se-á harmonia através do favorecimento das trocas entre as partes. Essa troca poderá ser fomentada pelos princípios da mediação expostos no trabalho do mediador com formação técnica e apropriada para lidar com a disputa.

d) por fim, evidencia-se que a resolução 174 do CSJT comete um equívoco ao prever que a mediação seja feita por magistrados e servidores. Não obstante a competência e o conhecimento desses profissionais (que não se discute) é necessário observar que eles são talhados para o confronto/disputa e que na maioria das vezes trabalharam nesse contexto por anos a fio. Como dizer a um juiz que ele não pode sugerir um acordo ou então mencionar como a mesma disputa vem sendo decidida em outros tribunais? Como pretender que esses profissionais se dispam de suas competências e trabalhem de modo oposto ao que sempre fizeram?

Mediação e jurisdição são mecanismos diferentes, complementares. Nas suas diferenças residem muitas hipóteses e oportunidades de lidar com as disputas. O mesmo pode ser dito de juízes e mediadores. Possuem prerrogativas e procedimentos 
diferentes, um decide, o outro facilita o diálogo, o primeiro diz a última palavra e põe fim ao processo, o segundo fomenta a palavra e a fala das partes. São misteres diferentes, labutas desenvolvidas por profissionais com habilidades e de formação diversas também.

Nesse contexto, a mediação realiza, através de uma pluralidade de formas, o fim que a jurisdição, na sua generalidade, parece negar ao singular: a possibilidade de recuperação daqueles espaços decisionais que a organização estatal, sempre invasiva e juridificada, passo a passo subtraiu. No entanto, opor a mediação a jurisdição significa recair na lógica conflitual da qual se busca a liberdade. Talvez seja melhor (e mais útil) considerá-los como instrumentos diferentes que se inserem em estados e níveis diversos na trama da conflitualidade.

Assim vista, de modo científico, a mediação poderá ser um mecanismo de lidar com as disputas de modo adequado e com qualidade, gerando satisfação para as partes que tomam em suas mãos as rédeas do seu destino.

\section{Referências}

Azevedo, André Gomma de (2001). Manual de Mediação Judicial. Brasília: Grupo de Pesquisa.

BaCellar, Roberto Portugal (2011). «O Poder Judiciário e o paradigma da guerra na solução de conflitos». In Peluso, Antônio Cesar, Morgana de Almeida Richa, (coords), Conciliação e mediação: Estruturação da Política Judiciária Nacional. Rio de Janeiro: Forense.

BArros, Felipe Luiz Machado (2016). «Aspectos polêmicos da lei 9.958/oo». Disponível em https://bit.ly/3cvAay1.

Blanchot, Maurice (1996). Pour l'amitié. Paris: Fourbis.

Bourdieu, Pierre (2006). O poder simbólico. Tradução de Fernando Tomaz (português de Portugal). 9. ${ }^{a}$ ed. Rio de Janeiro: Bertrand Brasil.

CAHAli, Francisco José (2015). Curso de arbitragem: Mediação, conciliação, Resolução CNJ 125/2010. São Paulo: Revista dos Tribunais.

Castelli, Stefano (1996). La mediazione. Milano: Raffaello Cortina.

Chase, Oscar G. (2014) Direito, cultura e ritual: Sistemas de resolução de conflitos no contexto da cultura comparada. Tradução de Sergio Arenhart e Gustavo Osna. São Paulo: Marcial Pons.

CosI, Giovanni (2004). «Interessi, diritti, potere. Gestione dei conflitti e mediazione». In ArsInterpretandi n. 9. Padova: CEDAM.

Cosi, Giovanni e Maria Antonieta Foddai (2003). Lo spazio della mediazione. Conflitti di diritti e confronto di interessi. Milano: Giuffrè.

Delgado, Mauricio Godinho (2019). Curso de direito do trabalho: obra revista e 
atualizada conforme a lei da reforma trabalhista e inovações normativas e jurisprudenciais posteriores. 18. ${ }^{a}$ ed. São Paulo: LTr.

Diniz, Maria Helena (2014). Curso de direito civil brasileiro: Teoria geral do direito civil. 31. ${ }^{\text {a }}$ ed. São Paulo: Saraiva.

Garapon, Antoine (1997). Bem Julgar: Ensaio sobre o ritual judiciário. Lisboa: Instituto Piaget.

HaYnes, John Michael (1993). Fundamentos de la mediación familiar como afrontar la separación de pareja de forma pacífica para seguir disfrutando de la vida. Madrid: Gaia Ediciones.

Horowitz, Irving Louis (1962). «Consensus, conflict and cooperation: a sociological inventory». Social Forces, 41.

Maluf, Clóvis Antonio e Maria Bernadete Miranda (2013). Curso Teórico e Prático de Mediação, Conciliação e Arbitragem. Rio de Janeiro: GZ.

MoraIs, José Luis Bolzan de e Fabiana Marion Spengler (2019). Mediação e Arbitragem. Alternativas à jurisdição. $4^{\mathrm{a}}$ ed. Porto Alegre: Livraria do Advogado.

Six, Jean François (2001). Dinâmica da mediação. Tradução de Giselle Groeninga de Almeida, Águida Arruda Barbosa e Eliana Riberti Nazareth. Belo Horizonte: Del Rey.

SolER, Raúl Cavo (2004). «I Giochi senza arbitro né segnapunti. La mancanza di certeza nella risoluzione dei conflitti». Traduzione Caterina Briguglia. In Ars Interpretande. Padova: Cedam, n. 9.

Souza JúnIOR, Cezar Saldanha (2002). Consenso e democracia constitucional. Porto alegre: Sagra Luzzatto.

SPEngler, Fabiana Marion (2016a). Da jurisdição à mediação: Por uma outra cultura no tratamento dos conflitos. 2 ed. Ijuí: Unijuí.

-. (2016b). Mediação de Conflitos. Da teoria à prática. Porto Alegre: Livraria do Advogado.

-. (2019a). Dicionário de mediação. Santa Cruz do Sul: Essere nel Mondo. v. 1. A-L.

-. (2019b). Dicionário de mediação. Santa Cruz do Sul: Essere nel Mondo, . v. 2. M-V.

Spengler, Fabiana Marion e Márcio Dutra da Costa (2019c). A mediação processual de conflitos coletivos trabalhistas. In: Fernanda Duarte et al. (org.), Escritos sobre direito, cidadania e processo: Discursos e práticas (pp. 239-262). Niterói: PPGSD, Programa de Pós-Graduação em Sociologia e Direito, v. II.

Spengler, Fabiana Marion e Theobaldo Spengler Neto (2013). A Resolução 125 do CNJ e o papel do terceiro conciliador e mediador na sua efetivação. Curitiba: Multideia.

-. (2016). Mediação, conciliação e arbitragem: Artigo por artigo. Rio de Janeiro: Editora FGV.

TARUfFo, Michele (1999). «Aspetti dela giustizia civille: frammentazione e privatizzazione». In Anuário de la Faculdad de Derecho de la Universidad Autónoma de Madrid, 3. 
TestaI, Anderson (2016). «Da inconstitucionalidade da Lei 9.958/200o nos dissídios individuais». Disponível em https://bit.ly/3dM6OvB.

Torres, Jasson Ayres (2005). O acesso à justiça e soluções alternativas. Porto Alegre: Livraria do Advogado.

Ventura, Deisy de Freitas Lima (2000). Monografia Jurídica: Uma visão prática. 2. ${ }^{\mathrm{a}}$ ed. Porto Alegre: Livraria do Advogado.

Weber, Max (1999). Economia e sociedade. Fundamentos da Sociologia Compreensiva. Tradução de Regis Barbosa e Karen Elsabe Barbosa. Brasília: UNB.

\section{Financiamento}

O presente texto foi produzido no âmbito do projeto: «O terceiro e o conflito: o mediador, o conciliador, o juiz, o árbitro e seus papeis políticos e sociais», financiado pela Fundação de Amparo a Pesquisa do Estado do Rio Grande do Sul, no Edital 02/2017, PqG FAPERGS, Pesquisador Gaúcho, processo 17/2551-0001169-4.

\section{Sobre o autor}

Fabiana Marion Spengler é pós-doutorada em Direito pela Università degli tudi di Roma Tre, na Itália. Doutor em Direito pela Universidade do Vale do Rio dos Sinos, Brasil. Mestre em Desenvolvimento Regional pela Universidade de Santa Cruz do Sul (UNISC), no Brasil. Professor dos cursos de graduação e pós-graduação da UNISC lato e stricto sensu. Coordenador do Grupo de Pesquisa «Políticas Públicas que Não Tratam Dois Conflitos», vinculado ao CNPq (Conselho Nacional de Desenvolvimento Científico e Tecnológico do Brasil). Autor de vários livros e artigos científicos. Correio eletrônico: fabiana@unisc.br. 